\title{
Induction Patterns of 70 Genes during Nine Days after Hepatectomy Define the Temporal Course of Liver Regeneration
}

\author{
Barbara A. Haber, ${ }^{* *}$ Kenneth L. Mohn, ${ }^{\star 5}$ Robert H. Diamond, ${ }^{*}$ and Rebecca Taub *\$ \\ ${ }^{*}$ Department of Genetics, ${ }^{\S}$ Howard Hughes Medical Institute, Division of Gastroenterology, ${ }^{\ddagger}$ Children's Hospital of Philadelphia, \\ Division of Gastroenterology, "Department of Medicine, University of Pennsylvania, School of Medicine, Philadelphia, \\ Pennsylvania 19104-6145
}

\begin{abstract}
Liver regeneration is an important process that allows for recovery from hepatic injuries caused by viruses, toxins, ischemia, surgery, and transplantation. Previously, we identified $>70$ immediate-early genes induced in regenerating liver after hepatectomy, 41 of which were novel. While it is expected that the proteins encoded by these genes may have important roles in regulating progression through the $G_{1}$ phase of the cell cycle during regeneration, we were surprised to note that many of these "early" genes are expressed for extended periods during the hepatic growth response. Here we define several patterns of expression of immediate-early, delayed-early, and liver-specific genes during the 9-d period after hepatectomy. One pattern of induction parallels the major growth period of the liver that ends at 60-72 $\mathrm{h}$ after hepatectomy. A second pattern has two peaks coincident with the first and second $G_{1}$ phases of the two hepatic cell cycles. A third group, which includes liver-specific genes such as $C / E B P \alpha$, shows maximal expression after the growth period. Although the peak in DNA synthesis in nonparenchymal cells occur $24 \mathrm{~h}$ later than in hepatocytes, most of the genes studied demonstrate similar induction in both cell types. This finding suggests that the $G_{0} / G_{1}$ transition occurs simultaneously in all cells in the liver, but that the $G_{1}$ phase of nonparenchymal cells may be relatively prolonged. Finally, we examined the expression of $>70$ genes in clinical settings that could induce liver regeneration, including after perfusion in a donor liver, hepatic ischemia, and fulminant hepatic failure. We found that a small number of early and liverspecific genes were selectively activated in human livers under these conditions, and we thereby provide a potential means of measuring the caliber of the regenerative response in clinical situations. (J. Clin. Invest. 1993. 91:1319-1326.) Key words: liver regeneration $\bullet$ gene expression $\bullet$ cell cycle $\bullet$ mitogenesis
\end{abstract}

\section{Introduction}

An understanding of the molecular mechanisms governing liver regeneration may be useful for designing therapies for patients with hepatitis, liver injury, or a liver transplant. Liver regeneration is also one of the few physiologic models of

Address correspondence to Dr. Rebecca Taub, Department of Genetics, Howard Hughes Medical Institute, University of Pennsylvania, School of Medicine, Philadelphia, PA 19104-6145.

Received for publication 14 August 1992 and in revised form 30 November 1992.

J. Clin. Invest.

(c) The American Society for Clinical Investigation, Inc. $0021-9738 / 93 / 04 / 1319 / 08 \quad \$ 2.00$

Volume 91, April 1993, 1319-1326 growth regulation. After a two-thirds partial hepatectomy in which the small lobes of the liver are left intact and without injury, the majority of liver cells reenter the cell cycle (1-5). The first round of DNA synthesis occurs at $12-16 \mathrm{~h}$ and the second, smaller round at $\sim 48 \mathrm{~h}$. By $1-2$ wk the liver has regained its original mass and the cells have again become quiescent. All components of liver tissue including bile duct epithelial cells, Ito cells, endothelial cells, Kupffer cells, and hepatocytes are involved in this process. For regeneration to be precisely carried out, multiple hepatic cell types must proliferate in a coordinated fashion. An orchestrated balance of positive and negative growth controls allows normal liver function and architecture to be maintained while the full-size organ is reconstituted.

The genes induced in the transition from the normal quiescent state of the liver $\left(G_{0}\right)$ to the growth phase $\left(G_{1}\right)$ are called immediate-early genes (6-15). Immediate-early genes are transcribed in response to a mitogenic stimulus even in the presence of cycloheximide-induced protein synthesis blockade. At the cellular level, proteins encoded by immediate-early genes may help control progression through $\mathrm{G}_{1}$. Previously, we identified $>70$ total and 41 novel immediate-early genes induced in regenerating liver and insulin-treated H35 rat hepatoma cells which have many properties of regenerating liver (14-16). Additionally, we defined patterns of gene expression in the liver induced by sham surgery and cycloheximide alone (15). In serum-treated fibroblasts $>100$ total immediate-early genes have been identified $(10,15)$, and we have found that approximately one-third of immediate-early genes show cell type-specific induction. While the number of genes involved in the immediate-early response is unusually large, such complexity may allow for a rapid cellular growth response.

Earlier, we noted that expression of many immediate-early genes remains elevated for longer than the initial $G_{1}$ phase of the cell cycle, but the temporal course of this expression during regeneration had not been clearly defined. Perhaps such immediate-early genes have ongoing roles during phases of the cell cycle in addition to $G_{1}$ that would allow fine tuning of the complex process of regeneration. Here, we have studied the temporal expression of immediate-early, delayed-early (protein synthesis-dependent induction), and other liver-specific genes from 0 to $9 \mathrm{~d}$ after hepatectomy, and found three characteristic patterns of expression that may relate to the regulation of regeneration and the physiologic role of specific gene products. Our data identify a temporal boundary at $60-72 \mathrm{~h}$ between the major growth period of the liver and the time during which high levels of expression of the liver-specific gene $C$ / $E B P \alpha$ begins. We show that hepatocytes and nonparenchymal cells show similar induction of gene expression. We describe a useful methodology for the analysis of injury and its repair as might be seen in clinical situations. 


\section{Methods}

Rat liver tissue preparation. Regenerating liver was obtained from Fischer rats (160-200 g). Rats were ether anesthetized and subjected to midventral laparotomy and subsequent removal of left lateral and median lobes ( $70 \%$ liver resection) by the method of Higgins and Anderson (17). Cycloheximide-treated samples were obtained by pretreating rats with an intraperitoneal injection of $50 \mathrm{mg}$ cycloheximide per $\mathrm{kg}$ body weight in a $5 \%$ phosphate-buffered saline solution $15 \mathrm{~min}$ before surgery (15). After the surgery, the animals were allowed to recover for times ranging from $30 \mathrm{~min}$ to $9 \mathrm{~d}$. Animals were then killed and the liver was immediately harvested. The isolated liver was rapidly homogenized in $4 \mathrm{M}$ guanidine thiocyanate buffer and stored at $-70^{\circ} \mathrm{C}$.

Human liver preparation. Livers were obtained at the time of surgery. A 4-8 g piece of liver was resected in the operating room and placed directly into $4 \mathrm{M}$ guanidine thiocyanate buffer. Homogenization was then performed and in all cases was completed within 5 min of the liver resection. The homogenized liver was then stored as above. Northern blots and ethidium-stained gels of the RNA showed no evidence of degradation (data not shown). Monkey liver Poly $\left(\mathrm{A}^{+}\right) \mathrm{RNA}$ was purchased from Clontech Laboratories, Inc., Palo Alto, CA). Patients described in Fig. 4 were as follows: "Donor," a human donor liver, normal on biopsy, preserved for $10 \mathrm{~h}$ in University of Wisconsin solution (18). "Ischemia," a sample taken from the right lobe of the liver of a 30-yr-old woman who was undergoing resection of the right lobe for benign hemangioma. The sample was taken $2 \mathrm{~h}$ after the blood supply to that lobe was surgically tied off, and did not contain the hemangioma tissue. And "FHF," a sample taken from the liver of a 10-yr-old male before undergoing liver transplant for fulminant hepatic failure, probably secondary to hepatitis $\mathrm{C}$. On biopsy, the sample showed massive necrosis, inflammation, and some proliferation of bile duct cells and hepatocytes.

Liver perfusion. Rats were ether anesthetized and subjected to midventral laparotomy and partial hepatectomy as above. At time 0 or at 3 $\mathrm{h}$ after partial hepatectomy the portal vein was catheterized, the inferior vena cava tied, and the thoracic inferior vena cava severed. The liver was perfused through the portal vein at a rate of $20 \mathrm{ml} / \mathrm{min}$ for 7 min with solution $A(142 \mathrm{mM} \mathrm{NaCl}, 6.7 \mathrm{mM} \mathrm{KCl}$, and $10 \mathrm{mM}$ HEPES, pH 7.4) and then 7 min with solution $\mathrm{C}$ (solution $\mathrm{A}+0.5$ $\mathrm{mg} / \mathrm{ml}$ collagenase; Boehringer Mannheim Corp., Indianapolis, IN). The procedure was carried out at $37^{\circ} \mathrm{C}$. At termination the liver was removed and minced in solution C on ice (19-21).

Separation of cell populations. After perfusion, the minced liver was filtered through gauze and then subjected to a single $200 \mathrm{~g}$ centrifugation for $5 \mathrm{~min}$ at $4^{\circ} \mathrm{C}$. The pellet was resuspended in $4 \mathrm{M}$ guanidine thiocyanate solution, the supernatant was spun at $400 \mathrm{~g}$ for $5 \mathrm{~min}$, and the resultant pellet was then resuspended in guanidine thiocyanate as above $(20,22)$. Efficiency of separation and cell viability were established using light microscopic trypan blue exclusion chamber counts (20).

RNA and Northern blots. RNA was isolated from thawed liver homogenates layered over a $5.6 \mathrm{M} \mathrm{CsCl}, 25 \mathrm{mM}$ sodium acetate cushion and centrifuged at $175,000 \mathrm{~g}$ for $18 \mathrm{~h}$. The RNA pellet was suspended in $\mathrm{dH}_{2} \mathrm{O}$, phenol- $\mathrm{CHCl}_{3}$ extracted, ethanol precipitated, and resuspended in $\mathrm{dH}_{2} \mathrm{O}$ (23). $10 \mu \mathrm{g}$ of total RNA as determined by $\mathrm{OD}_{260}$ was heat denatured and loaded on a Mops denaturing gel and transferred to Optibind-supported nitrocellulose (Schleicher \& Schuell, Keene, NH). ${ }^{32} \mathrm{P}$-labeled probes were made using the random prime plus kit (NEN/ DuPont, Boston, MA). Blots were hybridized at $42^{\circ} \mathrm{C}$ for $16 \mathrm{~h}$ in hybridization buffer consisting of $10 \%$ dextran sulfate, $40 \%$ formamide, $0.6 \mathrm{M} \mathrm{NaCl}, 0.06 \mathrm{M}$ NaCitrate, $7 \mathrm{mM}$ Tris, $\mathrm{pH}$ 7.6, 0.8 $\times$ Denhardt's solution, and $0.002 \%$ heat-denatured, sonicated salmon sperm DNA. After a low temperature wash, blots were washed twice for 10 min at $60^{\circ} \mathrm{C}$ in $0.015 \mathrm{M} \mathrm{NaCl}, 0.0015 \mathrm{M} \mathrm{NaCitrate,} 0.1 \%$ SDS before exposure to film (Kodak X-OMAT AR5).

Dot blot preparation and analysis. DNA dot blots were prepared with 1 or $2 \mu \mathrm{g}$ of recombinant plasmid DNA per dot prepared as recommended by Schleicher \& Schuell, Inc., filtered through a Minifold appa- ratus, and immobilized on Optibind nitrocellulose (15). $\left[\alpha{ }^{32} \mathrm{P}\right] \mathrm{dCTP}$ (New England Nuclear, Boston, MA) cDNA probes were synthesized from $55 \mu \mathrm{g}$ of total RNA using Moloney murine leukemia virus reverse transcriptase (GIBCO BRL, Gaithersburg, MD) primed with oligo dT. Blots were hybridized in $50 \%$ formamide, $0.75 \mathrm{M} \mathrm{NaCl} 0.075 \mathrm{M} \mathrm{NaCi}$ trate, $0.5 \%$ SDS, and $5 \times$ Denhardt's solution for $40 \mathrm{~h}\left(42^{\circ} \mathrm{C}\right.$, rat probes; $37^{\circ} \mathrm{C}$, human monkey probes). Blots were washed as described (15), including two 10 -min washes in $0.015 \mathrm{M} \mathrm{NaCl}, 0.0015 \mathrm{M}$ sodium citrate at $55^{\circ} \mathrm{C}$ (rat) or $40^{\circ} \mathrm{C}$ (monkey, human) before exposure to film. Exposure times were determined according to the level of signal for $\beta 2$-microglobulin, which was made equivalent for each probe. Dots containing plasmid controls ( $\mathrm{pGem}$, pBluescript) gave no signal at the exposure times used.

\section{Results}

Identification of three different temporal patterns of gene induction during liver regeneration. To define patterns of expression of immediate-early, delayed-early, and liver-specific genes during liver regeneration, we studied the temporal expression of these genes out to $9 \mathrm{~d}(216 \mathrm{~h})$ after partial hepatectomy. More than 70 cDNAs corresponding to these genes were immobilized on nitrocellulose membranes and these dot blots were hybridized with a probe made from RNA obtained from regenerating rat liver for each time point (see Methods). We were able to identify several different patterns of expression. Using a representative gene for each pattern of expression, we then performed Northern blot analyses to confirm the results obtained with dot blot analyses (Fig. 1, $A$ and $B$ ). $\beta 2$-Microglobulin is constitutively expressed and its expression was used as a normalization control for RNA loading. Although there was some difference in the degree of expression in dot blots and Northern blots, probably because of slight differences in normalization, the basic patterns of expression were the same.

The expression of $\beta$-actin, a gene encoding a structural protein, is induced within $30 \mathrm{~min}$, peaks by $8 \mathrm{~h}$, and returns to baseline by $\sim 60 \mathrm{~h}$, thus defining the temporal course of the hepatic growth period. We found that albumin mRNA is induced over a shorter time period, consistent with previously published dot blot results (14). In contrast, IGFBP-1 (insulinlike growth factor binding protein-1), a gene that encodes a secreted protein that may be involved in growth regulation (24), has two distinct peaks of expression concurrent with the $G_{1}$ phase of both the first and second hepatic cell cycles (see Fig. 2), suggesting that its regulation is cell cycle dependent, not growth dependent. The third pattern of expression is exemplified by the $C / E B P \alpha$ gene, which encodes a tissue-specific transcription factor (25). After partial hepatectomy, we find its expression is initially low and later increases with a broad peak between 60 and $216 \mathrm{~h}$ after hepatectomy, when the major growth period of the liver is complete. We have measured the expression of the $C / E B P \alpha$ gene after hepatectomy several times with different RNA samples, and our findings are consistent and compatible with what we reported earlier (14). These findings are somewhat different from Mischoulon et al. (26), who normalized the level of $C / E B P \alpha$ to albumin gene expression. They saw a two- to three-fold decrease in $C / E B P \alpha$ expression immediately after hepatectomy, and a return to baseline by $72 \mathrm{~h}$ after hepatectomy.

After normalization of dot blots and Northern blots, the expression patterns obtained for the genes shown in Fig. 1 were represented diagrammatically (Fig. 2) relative to the indicated temporal course of recovery of liver mass and DNA synthesis 


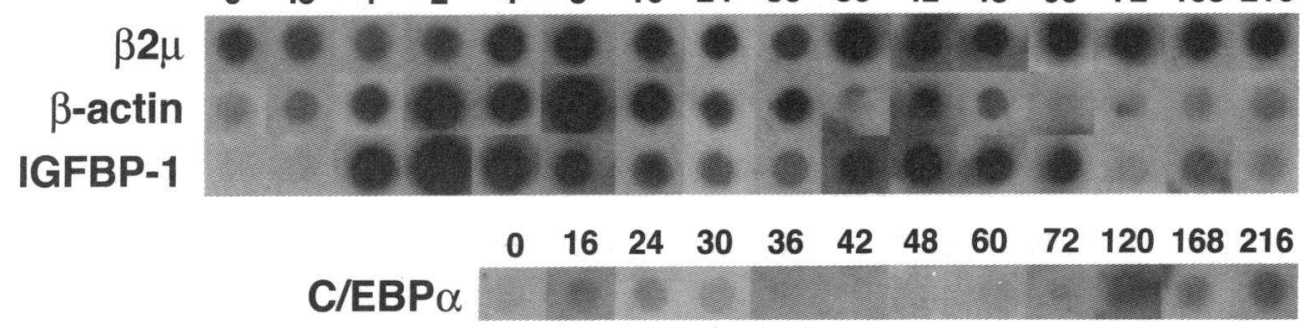

B
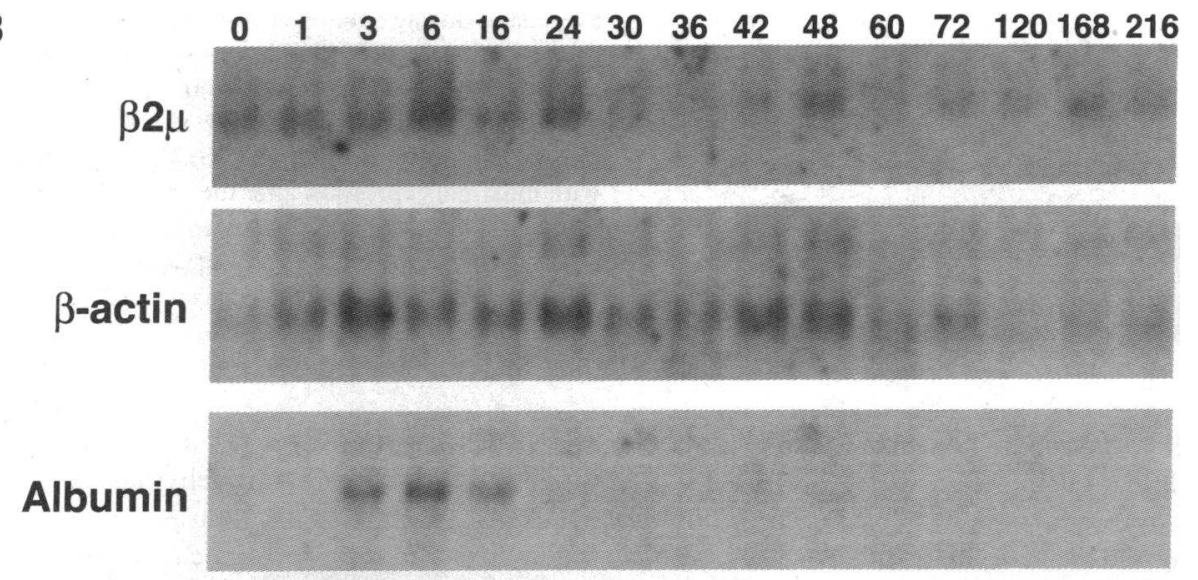

IGFBP-1

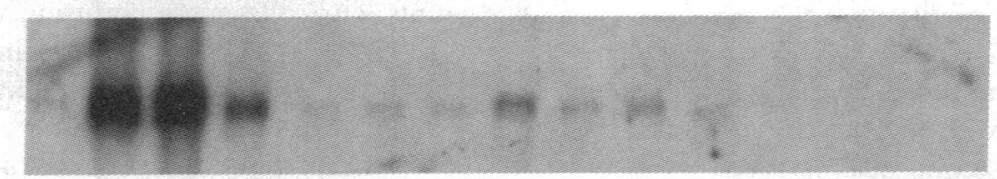

$\mathrm{C} / \mathrm{EBP} \alpha$

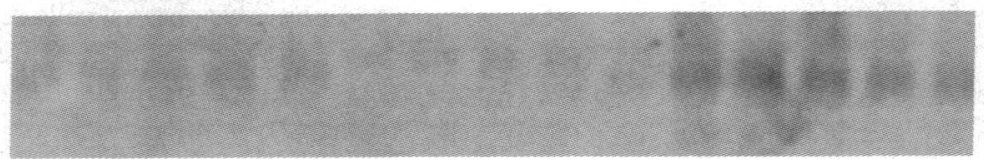

Figure 1. Dot blot and Northern blot analyses of genes induced during liver regeneration identify three patterns of regulated expression. Numbers above lanes are hours after hepatectomy. $\beta 2 \mu, \beta 2$-microglobulin. ( $A$ ) Dot blots, as explained in Methods. For comparison, the dot blot autoradiograms from $0.5-8 \mathrm{~h}$ after hepatectomy were taken from Mohn et al., 1991 (15) and were not available for C/EBP $\alpha$. (B) Northern blots of regenerating liver RNA hybridized with $\beta 2$ microglobulin, $\beta$-actin, albumin, $I G F B P-1$, and $C / E B P \alpha$ CDNA probes.

$(4,5,17)$ based on $\left[{ }^{3} \mathrm{H}\right]$ thymidine incorporation into hepatocytes and nonparenchymal cells after hepatectomy. Juxtaposition of the information shown in this figure highlights the events that are taking place during the regenerative process.

Analysis of expression of $>70$ genes demonstrates three basic patterns of gene induction. After normalization of dot blot and Northern blot results to the expression of constitutively expressed genes, we categorized the hepatic expression pattern from time 0 to $216 \mathrm{~h}$ after hepatectomy according to the three distinct patterns of regulated expression (Fig. 2) for $>70$ immediate-early, delayed-early, and liver-specific genes (summarized in Table I). The pattern of constitutive expression was seen for genes that are not induced after hepatectomy such as $\beta 2$-microglobin, ATP synthase, IGF-1, and ubiquitin. They are included in our analysis as they serve as normalization controls. We have indicated the time period of peak expression and the tissue-specific expression of these genes based on our previously published data $(14,15)$ and data in Fig. 3.

From earlier studies $(1,2)$, we know that the liver regains its size within 1-2 wk. The majority of this growth occurs in the first $72 \mathrm{~h}$ after partial hepatectomy. At $24 \mathrm{~h}$ the liver has been restored to half its size and by $72 \mathrm{~h}$ it has regained $>75 \%$ of its original mass. A large number of both known and novel genes are expressed in parallel with the major growth period of the liver. These genes include known structural genes such as $\beta$-actin and fibronectin. A number of transcription factors representing multiple transcription factor families, including JunB, cjun (leucine zipper) (14), RNR-1 (nuclear receptor) (Scearce, L. M., T. M. Laz, and R. Taub, manuscript submitted for publication), and egr-1 (zinc finger) (27), are in this group, but have a slightly different induction pattern. They show a large early $G_{1}$ peak of induction (unlike actin, which has a small early peak), and a subsequent low level of expression which ceases at 60-72 h. Some genes of unknown function also display this pattern, while others demonstrate an expression pattern more similar to actin. The delayed-early genes demonstrate a characteristic growth-regulated expression. Their expression occurs later and the peak is broader, ranging from 8 to $24 \mathrm{~h}$ after hepatectomy, and coincides with mid- $\mathrm{G}_{1}$ to mid-S phase.

After partial hepatectomy the liver rapidly traverses the cell cycle. More than $90 \%$ of cells participate in one round of the cell cycle and approximately one-third participate in two ( 1 , 2 ). We found that a variety of genes appear to be cell cycle 


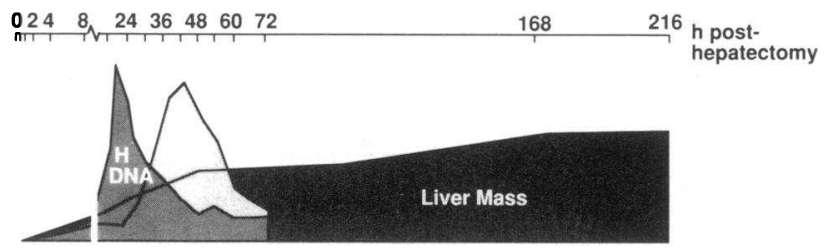

$\frac{\text { Induction }}{\text { Pattern }}$

Growth-
Regulated
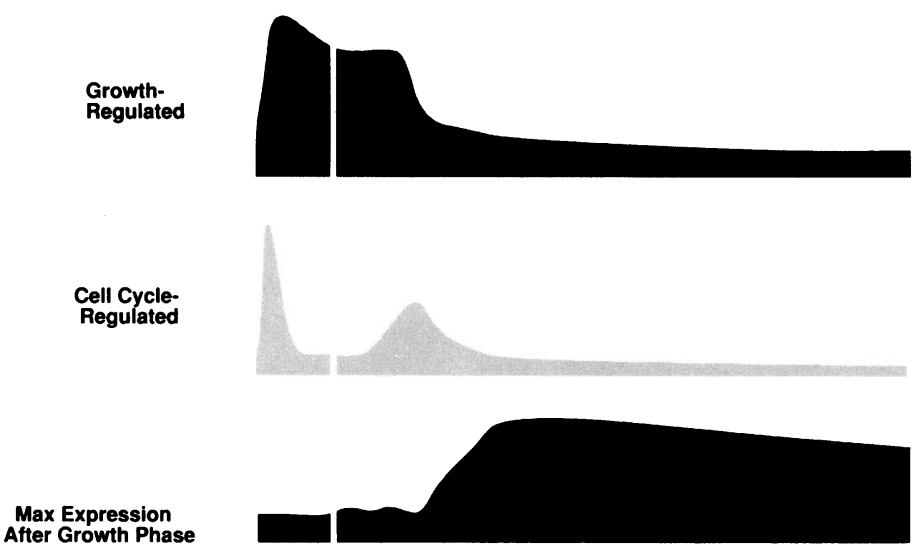

Figure 2. Representation of patterns of regulated gene expression during liver regeneration. Following densitometric tracings of Northern blots shown in Fig. 1, the pattern of gene expression is indicated for growth-regulated genes (example, $\beta$-actin), cell cycle-regulated genes (example, IGFBP-1), and genes with maximal expression after the growth phase (example, $C / E B P \alpha)$. Hours after hepatectomy and patterns of DNA synthesis in hepatocytes $(H)$ and nonparenchymal cells $(N P)$ and reaccumulation of liver mass are indicated $(4,5,17)$.

regulated with two peaks of expression correlating with the $G_{1}$ phases of the first and second rounds of cell division. Most typically there was a large first peak followed by a smaller, broader second peak that occurred after the first day. From our knowledge of cell kinetics, we would predict that the second peak coincides with the second $G_{1}$ phase of the hepatocyte cell cycle. At 36-48 h after hepatectomy, nonparenchymal cells are in the $S$ phase ( 5 ) and should not be expressing these genes, but we have not documented this. The second peak is broad, as would be expected as cells lose their synchrony.

Four genes demonstrate maximal expression after the major growth period of regeneration. Interestingly, two of these genes ( $C L-34$ and $C L-58$ ) were classified as immediate-early (15). In fact, their expression during the last $7 \mathrm{~d}$ of regeneration is equivalent to their expression $2 \mathrm{~h}$ after hepatectomy. While initial induction of these genes is stimulated by partial hepatectomy and does not require new protein synthesis, subsequent induction probably requires different factors. $C / E B P \alpha$, although not an immediate-early gene, demonstrates an even more interesting pattern of expression, as its maximal expression occurs $72-216 \mathrm{~h}$ after hepatectomy (see Fig. 2), correlating with the time when the liver stops growing. This is consistent with the proposed role of $\mathrm{C} / \mathrm{EBP} \alpha$ as an anti-proliferation factor (28).

Hepatocyte vs. nonparenchymal cell expression. Since liver regeneration involves the coordinated growth of multiple cell types, we were interested in the distribution of expression of these genes in different types of cells in the liver. The liver is composed of $60 \%$ hepatocytes and $40 \%$ nonparenchymal cells, of which the majority are Kupffer and endothelial cells, and $<5 \%$ are Ito, bile duct, and mesenchymal cells (29). Because of the rapid induction of immediate-early genes, we were restricted to using cell separation techniques that would allow the most rapid preservation of RNA. Therefore, our analysis of parenchymal and nonparenchymal cells was carried out after a short collagenase liver perfusion followed by a single centrifugation which separates hepatocytes from all other liver cells (20).
Elutriation, a more time-consuming procedure, has the advantage of separating the different nonparenchymal cells types (30), but could result in induction of a variety of genes and thus obscure the analysis. By trypan blue exclusion and cell chamber counts, our collagenase perfusion was reproducible with $>95 \%$ cell viability and $<1 \%$ contamination of nonparenchymal cells by hepatocytes and $<5 \%$ contamination of hepatocytes by nonparenchymal cells.

Fig. 3 shows the distribution of expression of various genes in hepatocytes and nonparenchymal cells at time zero and $3 \mathrm{~h}$ after partial hepatectomy/cycloheximide treatment compared with the same time points obtained from whole liver. We found a similar increase in gene expression after partial hepatectomy in the hepatocyte and nonparenchymal cells compared with whole liver, thus establishing the fact that this procedure does not interfere with induction after partial hepatectomy. Genes known to be cell type-specific such as PEPCK (phosphoenolpyruvate carboxy kinase ) and $I G F-1$ (24) were expressed only in the hepatocyte fraction as expected, thus demonstrating the purity of the separation. Lastly, as expected, delayed-early genes were not induced by this process.

Of the genes reported, expression of $80 \%$ was found in both hepatocytes and nonparenchymal cells, demonstrating that the initial proliferative response is similar in both populations. The response involves all classes of immediate-early genes including those encoding transcription factors, secreted factors, and structural proteins. This is consistent with what has been reported previously for c-jun (31), and indicates that although the onset of DNA synthesis is much later in nonparenchymal cells, the initial $G_{0} / G_{1}$ transition occurs within minutes of hepatectomy in both cell types.

The function encoded by many of the genes displaying cell type-specific expression is unknown. However, of those with known function, genes displaying cell type-specific expression include genes encoding liver-specific proteins like IGF-1, PEPCK, and liver-specific transcription factors like C/EBP $\alpha$ which are normally made in hepatocytes. $I P-10$, a gene first 
Table I. Pattern of Expression of Immediate-Early, Liver-specific Genes during Liver Regneration

\begin{tabular}{|c|c|c|c|c|c|c|c|c|c|c|}
\hline Pattern & Induction & Gene & $\begin{array}{l}\text { Tissue; } \\
\text { Hep, } \\
\text { NP }\end{array}$ & Peak Exp & Pattern & Induction & Gene & $\begin{array}{l}\text { Tissue; } \\
\text { Hep, } \\
\text { NP }\end{array}$ & \multicolumn{2}{|c|}{ Peak Exp } \\
\hline & & & & $h$ & & & & & $h$ & \\
\hline \multirow{41}{*}{$\begin{array}{l}\text { Growth- } \\
\text { regulated }\end{array}$} & IE & actin & Mult & 2 & & & $C L-38$ & Mult; & 24 & \\
\hline & & Gene 33 & Mult & 2 & & & & NP & & \\
\hline & & fibronectin & Mult & 2 & & & $C L-39$ & Liver & 8 & \\
\hline & & junB & Mult & 2 & & & $C L-61$ & Mult & 8 & \\
\hline & & $c$-jun & Mult & 1 & & & $C L-120$ & Mult & 24 & \\
\hline & & $J E$ & Mult & 2 & & & $C L-141$ & Mult & 24 & \\
\hline & & $R L-9$ (viral env. & Liver; & 2 & & & $C L-182$ & Mult & 24 & \\
\hline & & protein) & Hep & & & & $R L-104$ & Liver & 24 & \\
\hline & & albumin & Liver & 6 & Constitutive & & ATP synthase & Mult & $0-216$ & \\
\hline & & $P R L-1(S L-314)$ & Mult; & 3 & & & B2 Microglobulin & Mult & $0-216$ & \\
\hline & & & NP & & & & $I G F-1$ & Mult; & $0-216$ & \\
\hline & & RNR-1 (SL-332) & Liver & 1 & & & & Hep & & \\
\hline & & egr-1 & Mult & 2 & & & ubiquitin & Mult & $0-216$ & \\
\hline & & PEPCK & $\begin{array}{r}\text { Liver; } \\
\text { Hep }\end{array}$ & 2 & $\begin{array}{c}\text { Max expression } \\
\text { after growth }\end{array}$ & & eck & Mult & $48-216$ & \\
\hline & & $K C$ & Mult; & 2 & phase & & & & & \\
\hline & & & Hep & & & & C/EBP alpha & Mult; & $60-216$ & \\
\hline & & $c-m y c$ & Mult & 2 & & & & Hep & & \\
\hline & & c-ets & Mult; & 1 & & & $C L-34$ & Liver & $2-216$ & \\
\hline & & & Hep & & & & $C L-58$ & Liver & $2-216$ & \\
\hline & & C/EBPbeta & Mult & 2 & Cell cycle & IE & $c$-fos & Mult & 1 & 48 \\
\hline & & $C L-8$ & Mult & 2 & regulated & & $I G F B P-I$ & Liver & 2 & 36 \\
\hline & & $C L-20$ & Mult & 2 & & & $R L / I F-1(l k B)$ & Mult & 1 & 48 \\
\hline & & $C L-36$ & Mult & 2 & & & pip92 & Mult & 2 & 48 \\
\hline & & $C L-97$ & Mult; & 2 & & & $R L-30(3 C H 134)$ & Mult & 1 & 48 \\
\hline & & & Hep & & & & $L F R-I$ & Mult & 2 & 48 \\
\hline & & $C L-180$ & Liver & 2 & & & $I P-10$ & Mult; & 1 & 42 \\
\hline & & $C L-183$ & Mult & nd & & & & Hep & & \\
\hline & & $C L-211$ & Mult & 1 & & & $C L-6$ & Mult; & 3 & 48 \\
\hline & & $R L-27$ & Mult & nd & & & & Hep & & \\
\hline & & $R L-53$ & Mult & 2 & & & $C L-73$ & Mult; & 2 & 48 \\
\hline & & $S L-339$ & Mult & 1 & & & & Hep & & \\
\hline & & $S L-371$ & Mult & nd & & & $C L-142$ & Liver & 2 & 36 \\
\hline & $\mathrm{DE}$ & $H R S(C L-4)$ & Mult & 6 & & & $R L-1$ & Liver & 1 & 60 \\
\hline & & MHC class 1 & Mult; & 8 & & & $R L-98$ & Mult & 2 & 48 \\
\hline & & & Hep & & & & $S L-353$ & Mult & 1 & 48 \\
\hline & & tropomyosin & Mult & 24 & & $\mathrm{DE}$ & $C L-131$ & Liver & 1 & 24 \\
\hline & & alpha FNR & Mult & 24 & & S phase & Histone H3 & Mult & $16-24$ & \\
\hline & & beta FNR & Mult & 24 & Undetectable & & $E G F$ & & & \\
\hline & & $C L-20$ & Mult & 24 & & & EGF-receptor & & & \\
\hline & & $C L-22$ & Mult & 24 & & & $I G F$-receptor & & & \\
\hline & & $C L-31$ & Mult & 24 & & & $\begin{array}{l}\text { egr-2 } \\
\text { alpha-fetoprotein }\end{array}$ & & & \\
\hline
\end{tabular}

Pattern of expression, type of induction (IE, immediate-early; DE, delayed-early), tissue expression (Hep, hepatocytes; NP, nonparenchymal; Mult, multiple tissues), and peak exp (peak expression in hours is given for each gene). References for most genes are provided in reference 15 except for the following: PRL-1 (Diamond, R. H., D. E. Cressman, T. M. Laz, and R. Taub, manuscript submitted for publication); RNR-1 (Scearce, L. M., T. M. Laz, and R. Taub, manuscript submitted for publication); HRS (Diamond, R. H., K. Du, K. L. Mohn, V. M. Lee, B. A. Haber, D. S. Tewari, and R. Taub, manuscript submitted for publication); IGFBP-1 (24); $R L / I F-1$ (IkB $\alpha)(35) ; p i p 92$ (36); $R L-30(37) ; L R F-1$ (32).

cloned in lymphocytes, is not induced in mitogen-stimulated $3 \mathrm{~T} 3$ cells or $\mathrm{H} 35$ cells (15), and its expression is limited to hepatocytes. Although lymphocytes and Kupffer cells are related by their cell lineage, we do not detect expression in non- parenchymal cells, which include Kupffer cells. Interestingly, two other genes showing cell type-specific induction are the $K C$ gene, encoding a cytokine (6), and $R L-9$, encoding a viral envelope protein, which also showed cell type-specific mito- 

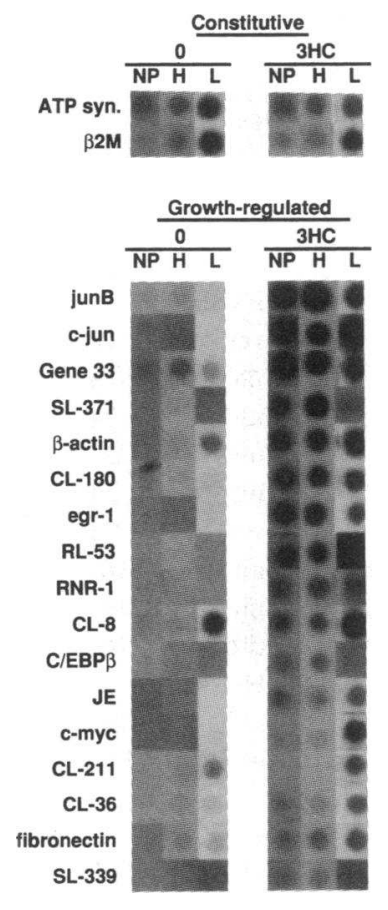
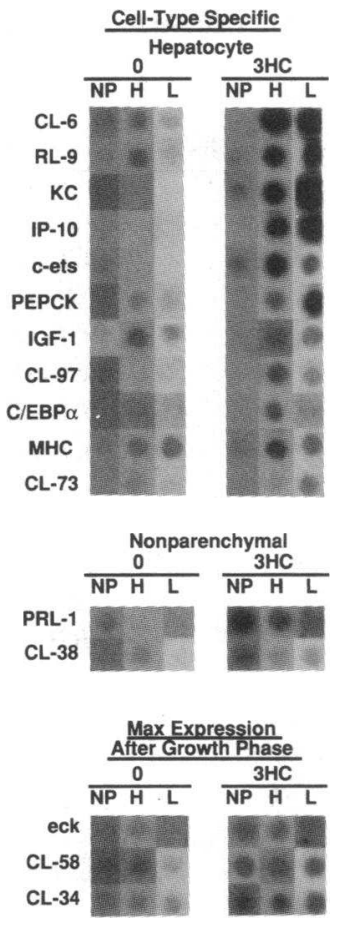
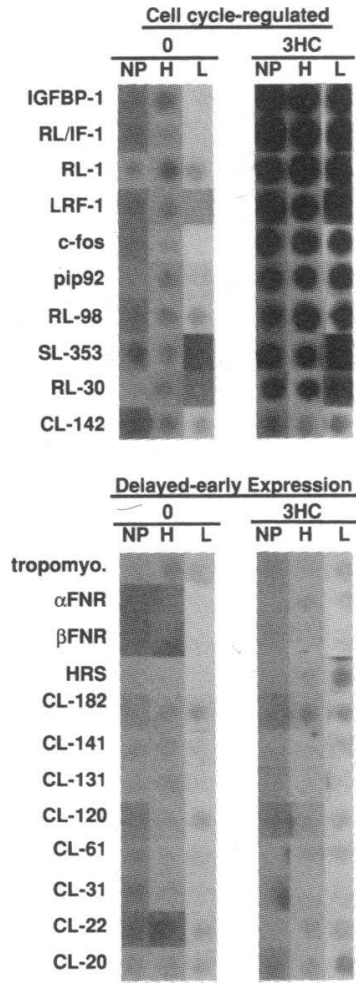

Figure 3. Similar induction of most genes in hepatocytes and nonparenchymal cells after hepatectomy. Results of dot blots for indicated genes are grouped according to overall expression patterns. $N P$, nonparenchymal cell RNA; $H$, hepatocyte RNA; $L$, total liver RNA; 0 , normal liver; $3 H C, 3 \mathrm{~h}$ after hepatectomy in the presence of cycloheximide. In some cases the lanes from Northern blots corresponding to normal liver and $3 \mathrm{~h}$ after hepatectomy were used. genic induction in our previous analysis (15). Surprisingly, several genes like $I G F B P-1$ and $R L-1$, which demonstrated induction only in regenerating liver and not mitogen-stimulated fibroblasts (15), did not show hepatocyte-specific expression.

Profile of the regenerative response in clinical settings. Previously, we found that the genes studied here are highly conserved between rat and human, and several of the rat cDNAs have been shown to readily detect the corresponding human mRNA on Northern blots (unpublished observations). We postulated that the dot blot analyses used here would prove useful in assessing the regenerative response of human liver in a variety of clinical settings. Using the same techniques as above, we made probes from RNA obtained from human livers and hybridized dot blots under slightly modified conditions (see Methods) to maximize hybridization to the rat cDNAs.

Fig. $4 \mathrm{~A}$ shows the data obtained from three different clinical settings and their comparison with normal rat and monkey liver. Only those genes with a different level of expression in the various human liver samples are shown. To confirm the results of the dot blot analyses, Northern blots were performed (Fig. 4 $B$ ) using probes for Gene33 and $R L-1$, which showed distinctly different levels of expression between the samples. Because of differences in RNA loading, the photograph of ethidiumstained ribosomal RNA subunits is shown. It was not possible to use monkey RNA, which was a small sample of Poly(A)+ RNA obtained as described in Methods. The level of expression in the dot blots was reflected in the Northern blots. RNA obtained from livers after $2 \mathrm{~h}$ of ischemia, or after the more prolonged insult of fulminant hepatic failure requiring liver transplantation, demonstrated a narrow range of immediateearly gene induction. Although the liver undergoing fulminant hepatic failure showed some evidence of a proliferative response on biopsy, this response was limited to relatively few cells, and mRNAs deriving from these cells would not be detect- able in total liver mRNA. Among the genes induced are $L R F$ 1 , which encodes a leucine zipper transcription factor and is normally one of the most highly induced immediate-early genes (32); IGFBP-1, which is also highly and rapidly induced in regenerating liver (24); and Gene33, which encodes a protein of unknown function and is highly induced by mitogenic and hormonal stimuli (14). As would be hoped, the clinical setting with the least perturbation from control rat liver was that obtained from a human donor liver preserved with University of Wisconsin solution and subsequently transplanted into a patient. Of the 12 genes shown, the expression of only two was significantly increased.

\section{Discussion}

The liver is one of the few organs that retains the capacity to regenerate after stimuli such as partial resection, toxic injury, ischemia, and transplantation. It is thus an excellent model for the study of growth regulation. The kinetics of liver regeneration after partial hepatectomy have been studied in detail with respect to DNA synthesis and restitution of size. At the molecular level, however, many questions have remained unanswered. Previous molecular analyses have focused on the transition from quiescence to growth. It has not been clear if proteins encoded by immediate-early and delayed-early genes have a continuing role throughout the time that it takes the liver to regain its size, or at the time that growth is curtailed.

Two patterns of mRNA induction, growth regulated and cell cycle regulated, appear to be linked to the proliferative phase of the liver. $G_{1}$ or cell cycle-specific expression of particular genes may result in variable levels of encoded proteins during the regenerative phase, which could have important influences on growth control. For example, like c-fos, LRF-1, a 

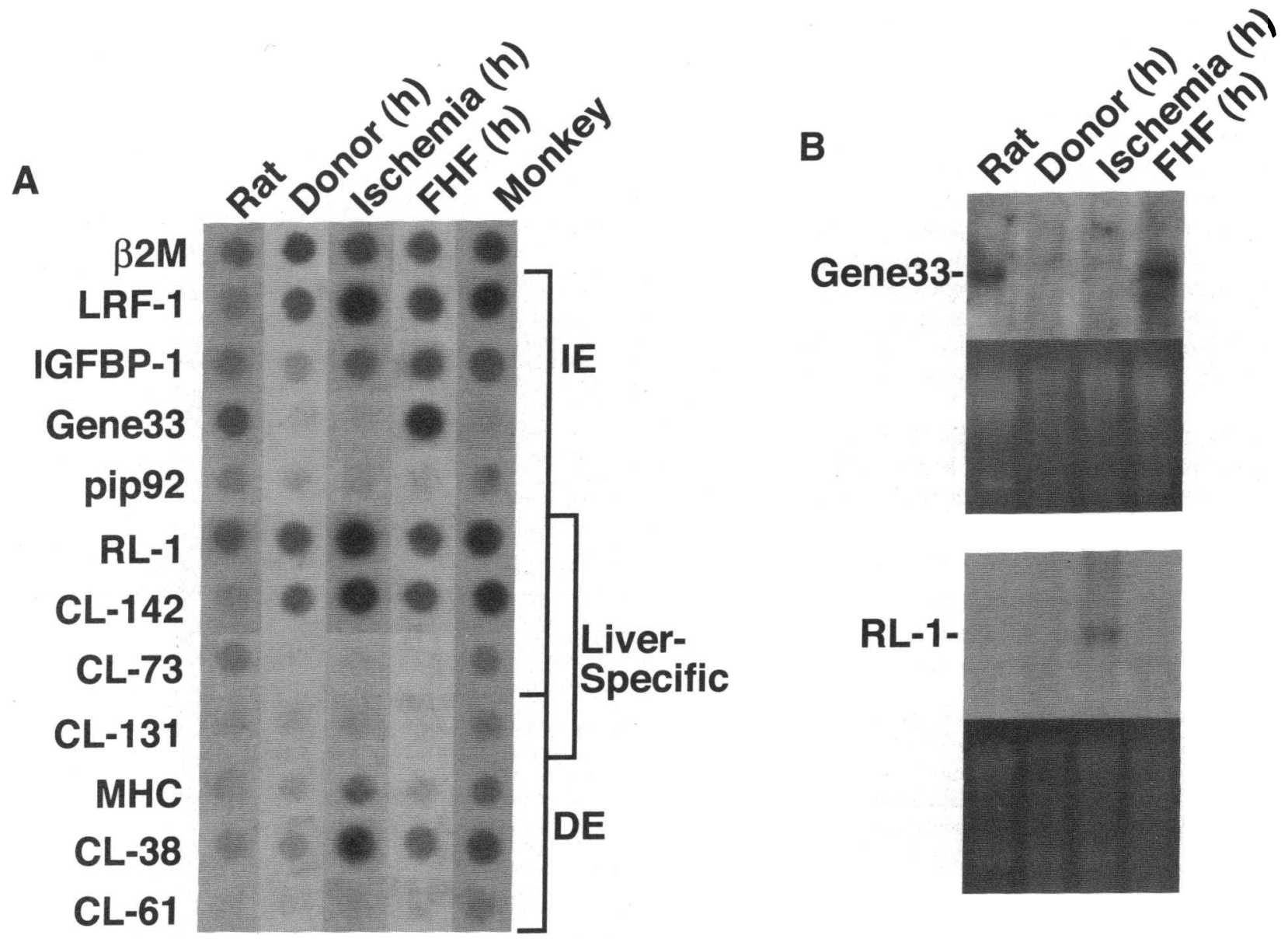

Figure 4. Dot blot analyses of human liver in different clinical settings demonstrate a subset of immediate-early gene induction. Patients are described in Methods. $F H F$, fulminant hepatic failure. $(B)$ Northern blot analyses using RNA samples in $4 A$, and Gene33 and $R L-1$ probes. Photograph of the ethidium bromide-stained ribosomal RNA subunits is shown below each autoradiogram.

leucine zipper transcription factor with cell cycle-regulated induction, forms heterodimers with both c-jun and JunB that are functionally very different (33). Depending on the relative level of LRF-1, c-fos, JunB, and c-jun at different times after hepatectomy, the relative level of each heterodimer will vary as will the transcriptional activity of target genes. The distinctive patterns of expression and the potential for multiple proteinprotein interactions add an additional level of complexity and allow for a more precise degree of growth control.

Given the enormous complexity of the immediate-early response after partial hepatectomy, it is likely that the immediate-early genes activate a blueprint for subsequent cellular events. Such a blueprint would allow for simultaneous activation of genes involved in initiation of growth as well as those involved in growth control that would cause the liver to return to its highly structured and nonproliferative state. By analysis of immediate-early, delayed-early, and liver-specific genes expressed from 0 to $9 \mathrm{~d}$ after partial hepatectomy, we are able to identify a boundary at $60-72 \mathrm{~h}$ following hepatectomy after which genes that demonstrate either growth or cell cycle-regulated expression are no longer induced, and at which another group of mostly liver-specific genes including $C / E B P \alpha$ become maximally expressed. C/EBP $\alpha$ has been shown to activate the transcription of several tissue-specific genes in a coordinated fashion. Its expression has been correlated with the dif- ferentiated state, and in some cells $\mathrm{C} / \mathrm{EBP} \alpha$ can arrest the proliferative phase $(25,29,34)$. The transition from expression of growth response genes to liver-specific genes at the time when the maximum growth period of the liver ends raises the possibility that liver-specific genes like $C / E B P \alpha$ encode proteins involved in reestablishing quiescence. However, only documentation of the presence of functional protein during the same time period that the mRNA is expressed will allow us to begin to unravel the complex interplay between positive and negative regulators of cell growth.

Even though liver regeneration is a complex, highly regulated process, patterns of expression of many genes after partial hepatectomy are similar in parenchymal and nonparenchymal cells. In a study of c-jun expression during liver regeneration, the finding of expression in mRNA populations from nonparenchymal and parenchymal cells was confirmed by in situ hybridization of whole liver sections (31). Genes identified as showing interesting cell type-specific expression in our study provide targets for subsequent in situ analyses. The response we observe is more similar between cell types in the liver than between regenerating liver and mitogen-treated fibroblasts (15). Growth factors (e.g., hepatocyte growth factor, unknown factors) that stimulate the hepatic response may act through different signal transduction pathways than growth factor (e.g., PDGF) which stimulate fibroblasts in culture. An alternative 
possibility is that liver-specific proteins that tailor the hepatic growth response may be important in maintaining cell-cell contacts and the architecture of the whole liver, which could require their expression in more than one hepatic cell type.

The analysis of liver growth and its control may have clinical ramifications. In these first studies of human livers, we were able to show that the dot blot analysis is a useful technique for simultaneous analysis of a panel of genes. Several hours of preservation of the donor liver did not result in induction of some genes that were induced after ischemia or massive liver necrosis. Both of these latter clinical settings were associated with the induction of a number of genes encoding transcription factors, growth factors, and a variety of genes of unknown function.

Potentially, this type of analysis could be used to predict which cases of ischemia or fulminant hepatic failure will ultimately require transplantation. Alternatively, the same techniques could be applied to assess the quality of donor livers, or measure the magnitude of the regenerative response after liver transplantation.

\section{Acknowledgments}

We thank Christina Hindman for help with surgery and cell preparations, Frank E. Yue for help with computer analyses, and Laurie Zimmerman for help with manuscript preparation.

This work was supported in part by National Institutes of Health (NIH) grants RO1 DK-44237 and JDF 190600 to R. Taub K11 DK01905 to B. A. Haber; and K11 DK-02096 to R. H. Diamond.

\section{References}

1. Fausto, N., and J. E. Mead. 1989. Regulation of liver growth: proto-oncogenes and transforming growth factors. Lab. Invest. 60:4-13.

2. Michalopoulos, G. K. 1990. Liver regeneration: molecular mechanism of growth control. FASEB (Fed. Am. Soc. Exp. Biol.) J. 4:176-187.

3. Leffert, H. L., K. S. Koch, P. I. Lad, H. Skelly, and B. de Hemptinne. 1982. Hepatocyte growth factors. In Hepatology. D. Zakim and T. D. Boyer, editors. W. B. Saunders Company, Philadelphia. 64-75.

4. Bucher, N. L. R., and M. N. Swaffield. 1975. Synergistic action of glucagon and insulin in regulation of hepatic regeneration. Adv. Enzyme Regul. 13:281293.

5. Grisham, J. W. 1962. A morphologic study of deoxyrobonucleic acid synthesis and cell proliferation in regenerating rat liver: autoradiography with thymidine-H. Cancer Res. 22:842-849.

6. Cochran, B. H., A. C. Reffel, and C. D. Stiles. 1983. Molecular cloning of gene sequences regulated by platelet-derived growth factor. Cell. 33:939-947.

7. Lau, L. F., and D. Nathans. 1985. Identification of a set of genes expressed during the G0/G1 transition of cultured mouse cells. EMBO (Eur. Mol. Biol. Organ.) J. 4:3145-3151.

8. Lau, L. F., and D. Nathans. 1987. Expression of a set of growth-related immediate early genes in BALB/c3T3 cells: coordinate regulation with c-fos or c-myc. Proc. Natl. Acad. Sci. USA. 84:1182-1186.

9. Lim, R. W., B. C. Varnum, and H. R. Herschman. 1987. Cloning of tetradecanoyl phorbol ester-induced primary response sequences and their expression in density-arrested Swiss 3T3 cells and a TPA non-proliferative variant. Oncogene. 1:263-270.

10. Almendral, J. M., D. Sommer, H. MacDonald-Bravo, J. Burkhardt, J. Perera, and R. Bravo. 1988. Complexity of the early genetic response to growth factors in mouse fibroblasts. Mol. Cell. Biol. 8:2140-2148.

11. Zipfel, P. F., S. G. Irving, K. Kelly, and U. Siebenlist. 1989. Complexity of the primary genetic response to mitogenic activation of human T cells. Mol. Cell. Biol. 9:1041-1048.

12. Herschman, H. R. 1991. Primary response genes induced by growth factors and tumor promoters. Annu. Rev. Biochem. 60:281-319.
13. Kruijer, W., H. Skelly, F. Botteri, H. van der Putten, J. R. Barber, I. M. Verma, and H. L. Leffert. 1986. Proto-oncogene expression in regenerating liver is stimulated in cultures of primary adult rat hepatocytes. J. Biol. Chem. 261:7929-7933.

14. Mohn, K. L., T. M. Laz, A. E. Melby, and R. Taub. 1990. Immediateearly gene expression differs between regenerating liver, insulin-stimulated H-35 cells, and mitogen-stimulated balb/c 3T3 cells. J. Biol. Chem. 265:21914-21921.

15. Mohn, K. L., T. M. Laz, J.-C. Hsu, A. E. Melby, R. Bravo, and R. Taub. 1991. The immediate-early growth response in regenerating liver and insulinstimulated $\mathrm{H} 35$ cells: comparison with serum-stimulated $3 \mathrm{~T} 3$ cells and identification of 41 novel immediate-early genes. Mol. Cell. Biol. 11:381-390.

16. Taub, R., A. Roy, R. Dieter, and J. Koontz. 1987. Insulin as a growth factor in rat hepatoma cells: stimulation of proto-oncogene expression. J. Biol. Chem. 262:10893-10897.

17. Higgins, G. M., and R. M. Anderson. 1931. Experimental pathology of the liver. I. Restoration of the liver of the white rat following partial surgical removal. Arch. Pathol. 12:186-202.

18. Jamieson, N. V. 1991. Review article: improved preservation of the liver for transplantation. Aliment. Pharmacol. Ther. 5:91-104.

19. Gores, G. J., L. J. Kost, and N. F. LaRusso. 1986. The isolated perfused rat liver: conceptual and practical considerations. Hepatology. 6:511-517.

20. Seglen, P. O. 1976. Preparation of isolated rat liver cells. Methods Cell Biol. 13:30-83.

21. Wolkoff, A. W., K. L. Johansen, and T. Goeser. 1987. The isolated perfused rat liver: preparation and application. Anal. Biochem. 167:1-14.

22. Hendriks, H. F. J., A. Brower, and D. L. Knook. 1990. Purification of liver cell types. Methods Enzymol. 190:54-58.

23. Davis, L., M. Dibner, and J. Battey. 1986. Basic Methods in Molecular Biology. Elsevier Science Publishing Co., Inc., New York.

24. Mohn, K. L., A. E. Melby, D. S. Tewari, T. M. Laz, and R. Taub. 1991. The gene encoding rat insulin-like growth factor binding protein-1 is rapidly and highly induced in regenerating liver. Mol. Cell. Biol. 11:1393-1401.

25. Birkenmeier, E. H., B. Gwynn, S. Howard, J. Jerry, J. I. Gordon, W. H. Landschulz, and S. L. McKnight. 1989. Tissue-specific expression, developmental regulation, and genetic mapping of the gene encoding CCAAT/enhancer binding protein. Genes \& Dev. 3:1146-1156.

26. Mischoulon, D., B. Rana, N. L. R. Bucher, and S. R. Farmer. 1992. Growth-dependent inhibition of CCAAT enhancer-binding protein (C/EBP) gene expression during hepatocyte proliferation in the regenerating liver and in culture. Mol. Cell Biol. 12:2553-2560.

27. Sukhatme, V. P., S. Kartha, F. G. Toback, R. Taub, R. Hoover, and C. Tsai-Morris. 1987. A novel early growth response gene rapidly induced by fibroblast, epithelial cell and lymphocyte mitogens. Oncogene Res. 1:343-356.

28. Umek, R. M., A. D. Friedman, and S. L. McKnight. 1991. CCAAT-enhancer binding protein: a component of a differentiation switch. Science (Wash. DC). 251:288-291.

29. Arias, I. M., W. B. Jakoby, H. Popper, D. Schacter, and D. A. Shafritz. 1988. Introduction: organizational principles. In The Liver: Biology and Pathobiology. I. M. Arias, W. B. Jakoby, H. Popper, D. Schachter, and D. A. Shafritz, editors. Raven Press, New York. 3-6.

30. Knook, D. L., N. Blansjaar, and E. C. Sleyster. 1977. Isolation and characterization of Kupffer and endothelial cells from the rat liver. Exp. Cell Res. 109:317-329.

31. Alcorn, J. A., S. P. Fietelberg, and D. A. Brenner. 1990. Transient induction of c-jun during hepatic regeneration. Hepatology. 11:909-915.

32. Hsu, J.-C., T. M. Laz, K. L. Mohn, and R. Taub. 1991. LRF-1, a novel leucine-zipper protein rapidly and highly induced in regenerating liver. Proc. Natl. Acad. Sci. USA. 88:3511-3515.

33. Hsu, J.-C., R. Bravo, and R. Taub. 1992. Interactions between LRF-1, JunB, c-Jun and c-Fos define a regulatory program in the $G_{1}$ phase of liver regeneration. Mol. Cell. Biol. 12:4654-4665.

34. Christy, R. J., K. H. Kaestner, D. E. Geiman, and M. D. Lane. 1991. CCAAT/enhancer binding protein gene promoter: binding of nuclear factors during differentiation of 3T3-L1 preadipocytes. Proc. Natl. Acad. Sci. USA. 88:2593-2597.

35. Tewari, M., P. Dobrzanski, K. L. Mohn, J.-C. Hsu, R. Bravo, and R. Taub. Rapid induction in regenerating liver of RL/IF-1, an IkB that inhibits NF-kB, RelB-p50 and c-Rel-p50; and PHF, a novel kB site binding complex. Mol. Cell. Biol. 12:2898-2908.

36. Charles, C. H., J. S. Simske, T. P. O’Brien, and L. F. Lau. 1990. Pip92: a growth factor-inducible protein in BALB/c 3T3 and PC12 cells. Mol. Cell. Biol. 10:6769-6774.

37. Charles, C. H., A. S. Abler, and L. F. Lau. 1992. cDNA sequence of a growth factor-inducible immediate early gene and characterization of its encoded protein. Oncogene. 7:187-190. 